\title{
Location of parathyroid adenomas by thallium-201 and technetium-99m subtraction scanning
}

\author{
A E YOUNG, JUDITH I GAUNT, D N CROFT, R E C COLLINS, C P WELLS, A J COAKLEY
}

\begin{abstract}
Solitary parathyroid adenomas were correctly located before surgery in 20 out of 21 cases by using ${ }^{201 \mathrm{~m} T 1}$ and ${ }^{99 m} \mathrm{Tc}$ in a subtraction technique. The technique was not useful in identifying hyperplastic parathyroid glands.

The technique is recommended as a useful procedure before surgery for primary hyperparathyroidism.
\end{abstract}

\section{Introduction}

A reliable method for locating abnormal parathyroid glands would be of great value to surgeons. Many non-invasive tests have been tried. Cineoesophagography ${ }^{1}$ and thermography ${ }^{2}$ were unhelpful, but ultrasound, using high resolution real time instruments, was more accurate. ${ }^{34}$ Computed tomographic (CT) scanning, at first found to be inaccurate, has recently achieved better results. ${ }^{5}$ None of these truly non-invasive techniques, however, is reliable enough to justify widespread adoption. Arteriography and selective venous sampling for differential parathyroid hormone analysis are more accurate but are difficult, expensive, and time consuming and carry a definite morbidity. Radioisotope scintigraphy ${ }^{6}$ is potentially of greater value, particularly before re-exploration of the neck for residual or recurrent parathyroid disease when previous surgery has deranged the fat and fascial planes needed for the interpretation of CT scans and ultrasound recordings and may have destroyed the normal vascular anatomy crucial to the success of venous sampling and angiography.

Attempts at detecting parathyroid adenomas with ${ }^{75} \mathrm{Se}-$ selenomethionine and ${ }^{131} \mathrm{Cs}$-caesium chloride have been unsatisfactory. ${ }^{201} \mathrm{Tl}$-thallous chloride has better imaging properties, and preliminary reports ${ }^{7-9}$ suggest that it is a superior agent for identifying parathyroid tissue. Because thallium is also taken up by the thyroid gland we have used a subtraction technique which removes a ${ }^{99 \mathrm{~m}} \mathrm{Tc}$ thyroid image, leaving the parathyroid tumour as a "hot" area. We report the results of this method in our first 34 patients with hyperparathyroidism who underwent subsequent surgical exploration of the neck.

\section{Patients and methods}

We studied 34 consecutive patients referred for parathyroid surgery for biochemically proved hyperparathyroidism. The diagnosis was usually based on a normal or raised parathyroid hormone concentration in the presence of hypercalcaemia and hypophosphataemia and the absence of clinical evidence of malignancy. Eight of the patients were undergoing renal dialysis. Subsequent surgical exploration disclosed a solitary parathyroid adenoma in 22 patients, a double adenoma in one, four gland hyperplasia in nine, and four normal parathyroid

St Thomas's Hospital, London SE1 7EH

A E YOUNG, MCHIR, FRCS, consultant surgeon

JUDITH I GAUNT, BSC, principal physicist

D N CROFT, DM, FRCP, consultant physician

Kent and Canterbury Hospital, Canterbury, Kent

R E C COLLINS, FRCS, FACS, consultant surgeon

C P WELLS, MSC, principal physicist

A J COAKLEY, MSC, MRCP, consultant physician glands with sarcoidosis in adjacent lymph nodes in one further patient. The remaining patient was explored for persisting hyperparathyroidism $\overrightarrow{\vec{\rho}}$ after two previous neck explorations, and three confluent deposits of parathyroid tissue were found. Scanning was performed in all cases before surgery.

\section{SCANNING TECHNIQUE}

Double tracer images were obtained using $99 \mathrm{~m} \mathrm{Tc}$ as sodium pertech- $\vec{\circ}$ netate for thyroid imaging and ${ }^{201} \mathrm{Tl}$ as thallous chloride for thyroid $\overrightarrow{\vec{\omega}}$ and parathyroid imaging. Data were acquired using a gammacamera ${ }_{O}$ with either a pin hole or converging collimator with on line computer $O$ facilities. Patients were given $35-75 \mathrm{MBq}(0.95-2 \cdot 03 \mu \mathrm{Ci}){ }^{99 \mathrm{~m}} \mathrm{Tc} \underline{Z}$. intravenously ( $35 \mathrm{MBq}$ at St Thomas's Hospital and $75 \mathrm{MBq}$ at Kent

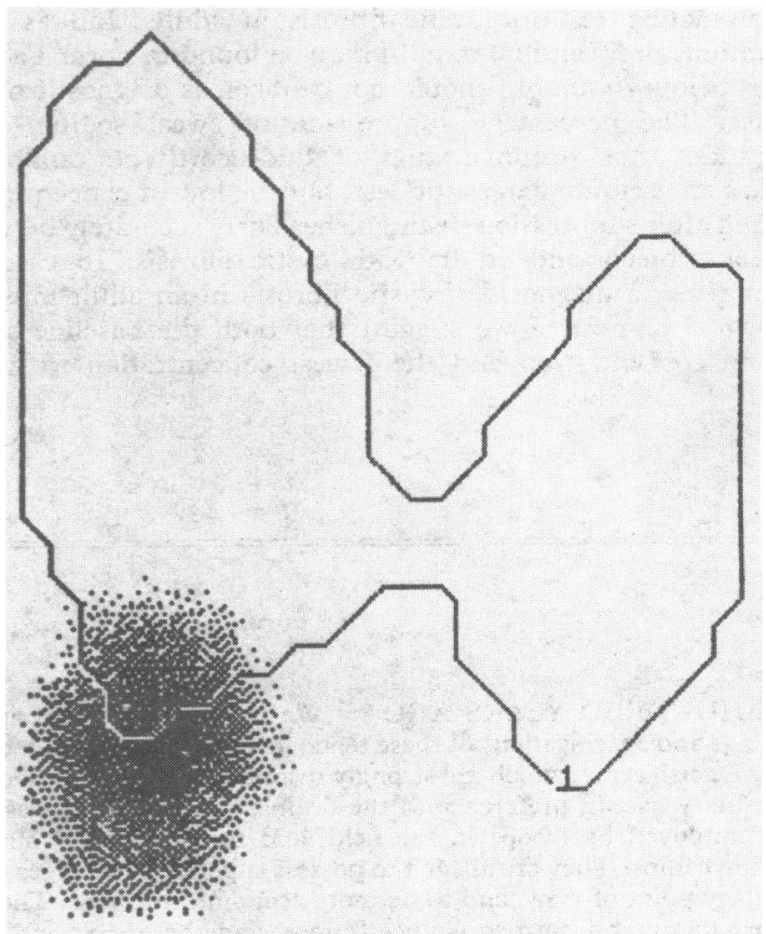

FIG 1 -Scan of $1.5 \mathrm{~cm}$ diameter solitary parathyroid adenoma. Continuous line marks edge of thyroid as visualised in technetium scan.

and Canterbury Hospital). Twenty minutes later an anterior image of $\sigma$ the thyroid was taken for five minutes followed by a five minute image of the technetium scatter within the thallium window settings. Anc injection of $75 \mathrm{MBq}{ }^{201} \mathrm{Tl}$ (thallous chloride) was then given intraven- $\mathbb{D}$ ously and images obtained dynamically for 30 minutes with the patient:remaining in the same position, perfectly still. All data were stored in $\frac{0}{0}$ the computer for subsequent processing.

The thallium images were summed, technetium scatter subtracted, $\stackrel{\mathbb{D}}{\Omega}$ and the technetium image then subtracted from the corrected thallium image. The final result was displayed with the outline of the technetium thyroid image superimposed (fig 1 and 2). A written prediction of the site of the adenoma was made before surgery.

Operation was a standard formal neck exploration with a view to identifying and excising or sampling for biopsy at least four parathyroidê glands in each patient. 


\section{Results}

One patient moved during the scan and the result could not therefore be interpreted. At operation a solitary adenoma was found; this patient is excluded from the results. The scans of all other patients were of good quality. One patient was scanned twice, six weeks apart, with identical results (fig 3). Another was scanned again five days after the first operation had found only four normal parathyroid glands. The hot spot was again seen and re-exploration disclosed an adenomatous fifth parathyroid behind the carotid sheath.

Of the 21 solitary adenomas found at operation, 20 were correctly located by the scan. The maximum diameter of the adenomas ranged from $7 \mathrm{~mm}$ to $35 \mathrm{~mm}$. The reason for failing to locate the adenoma in one case was not apparent; the missed tumour was 25 by $10 \mathrm{~mm}$ in diameter. In the patient with two adenomas, both were identified.

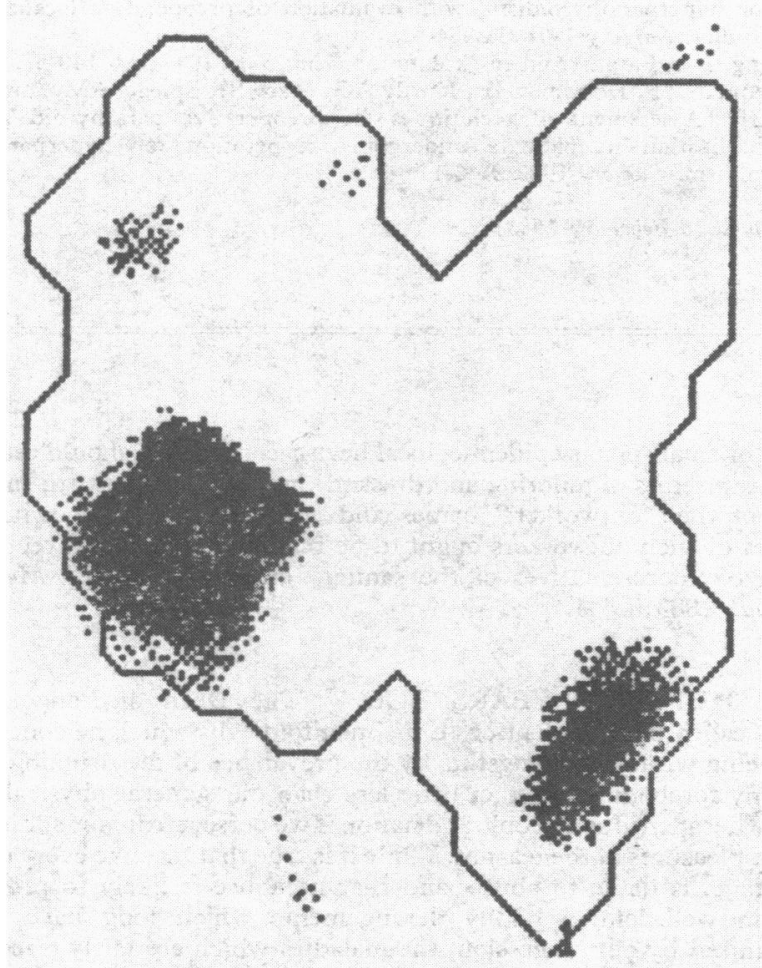

FIG 2-Scan of patient with tertiary hyperparathyroidism. Left upper parathyroid not shown.

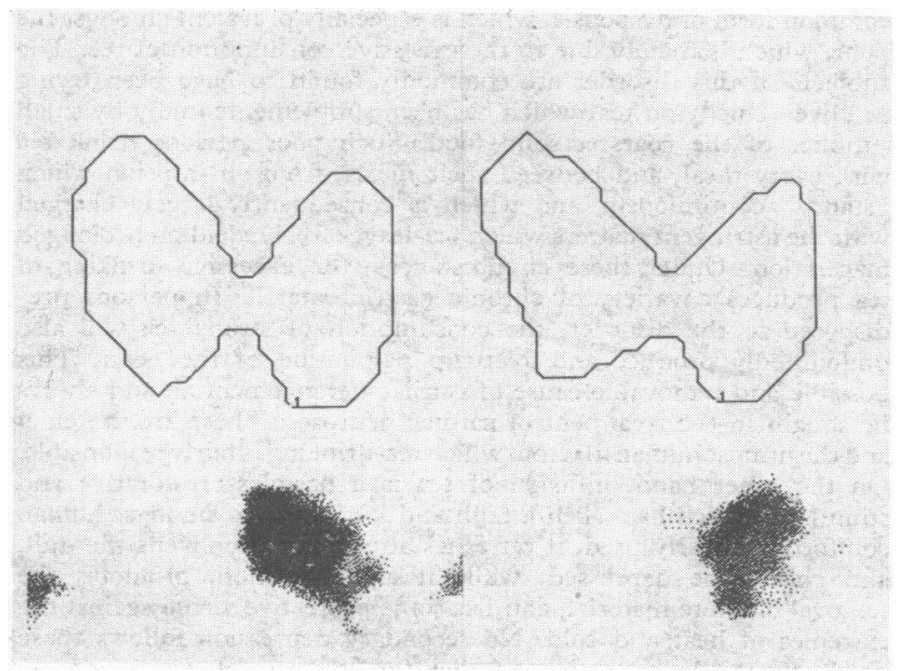

FIG 3-Scans of patient with $1.0 \mathrm{~cm}$ diameter parathyroid adenoma performed on two occasions six weeks apart. Adenoma located in upper horn of thymus.
Among the nine patients with four gland hyperplasia, 20 glands were identified in the scans. Sixteen glands were not identified. Of these, six had a maximum diameter of less than $5 \mathrm{~mm}$, one was leaf like and its volume was small, and three were overlapped by other parathyroid tissue. There was no apparent reason for the failure to image the remaining six.

There were two false positive scans. In one case two hot spots were seen, one turning out to be a parathyroid adenoma and the other a thyroid adenoma. In the other case four normal parathyroid glands were located, the hot spot being an enlarged lymph node affected by sarcoidosis.

Surgeons' opinions-The surgeons considered that the scans were particularly helpful on 10 occasions: in one case by locating recurrent parathyroid tissue; in three cases by locating intrathymic parathyroid adenomas; in one case by locating an intrathyroid parathyroid adenoma; in two cases by identifying ectopic parathyroid tissue behind the carotid sheath (in one instance a fifth parathyroid); in two cases by helping a dissection made difficult by previous thyroid surgery; and in one case allowing a quick operation in an unfit patient.

\section{Discussion}

The purpose of this study was to determine whether parathyroid adenomas could be reliably located by the technique described. We did not therefore use the test diagnostically but studied only patients in whom a decision had already been made to explore the neck. The results show that solitary parathyroid adenomas larger than $5 \mathrm{~mm}$ diameter may be reliably located not only in normal anatomical positions but also elsewhere in the neck, including those within the thyroid gland and in the cervical and upper mediastinal thymus. None of our patients had a low mediastinal parathyroid adenoma, but detection in that site may be difficult because of high myocardial activity. In two reexplorations the site of the parathyroid tissue was accurately predicted by the scan. Although the scans were persistently successful in locating parathyroid adenomas, only 20 of the 36 glands affected in four gland hyperplasia were located. A single hot spot on the scan does not therefore exclude four gland hyperplasia. The parathyroid glands in these patients were not uniformly enlarged, and the failures were in some instances due to the glands being too small to be detected and in others due to glands overlapping one another when viewed from the front of the neck. A reason for failure to detect some enlarged hyperplastic glands was not, however, clear. Although the glands may be morphologically similar to adenomas, their functional ability to trap thallous chloride may be different. Counting statistics makes the detection of multiple small glands more difficult than larger, solitary ones.

Scanning with ${ }^{75} \mathrm{Se}$-selenomethionine has been advocated by some workers ${ }^{1011}$ but the poor energy characteristics and high radiation dose to patients has caused most centres to abandon the technique. Thallium- ${ }^{201}$ has better energy characteristics for gammacamera use and gives a lower radiation dose.

It has been proposed that locating abnormal parathyroid glands preoperatively is indicated only before reoperation for recurrent or persisting hyperparathyroidism. The surgeons in this study, however, found that the scans had been helpful in a third of the patients who were being explored for the first time, and on three occasions the operation was substantially altered by the scan findings. Some 5\% of first explorations for parathyroid adenomas fail because the gland, although present in the neck, is not located. ${ }^{12}$ Subsequent reoperation is not only technically difficult but the results are unsatisfactory in terms of re-establishing normocalcaemia. ${ }^{13-15}$ Hence there is a strong argument for attempting to locate the glands before every first exploration as a way of reducing the incidence of missed adenomas. Because most undetected adenomas are in the neck or upper thymus ${ }^{13-16}$ they should be readily detectable by a scintigraphic technique.

An effective isotopic technique for locating residual or recurrent parathyroid tissue is even more valuable before reoperation, for even in experienced hands the success of angiography and venous sampling for detection has been found to be 
no better than $50 \% \cdot{ }^{17}$ Our experiences suggest that, in contrast, subtraction scanning, which is non-invasive, may be the most efficient method at present available.

We thank Mr T Bates, of Ashford Hospital, Kent, for permission to include one case studied by us but operated on by him.

\section{References}

1 Stevens AC, Jackson CE. Localization of parathyroid adenomas by Esophageal cine-roentgenography. American fournal of Roentgenology 1967;99:233-7.

2 Samuels BL, Dowdy AH, Lecky JW. Parathyroid thermography. Radiology 1972;104:575-8.

${ }^{3}$ Simeone JF, Mueller PR, Ferrucci JT, et al. High-resolution real-time sonography of the parathyroid. Radiology $1981 ; 141: 745-51$.

${ }^{4}$ Scheible W, Deutsch AL, Leopold GR. Parathyroid adenoma: accuracy of preoperative localization by high-resolution real-time sonography. fCU $1981 ; 9: 325-30$.

${ }^{5}$ Doppman JL. CT localization of cervical parathyroid glands: it deserves a second look. F Comput Assist Tomogr 1982;6:519-20.

${ }^{6}$ Ferlin G, Conte N, Borsato N, et al. Parathyroid scintigraphy with ${ }^{131} \mathrm{Cs}$ and ${ }^{201}$ Tl. F Nucl Med Allied Sci $1981 ; 25: 119-23$.

${ }^{7}$ Ferlin G, Borsato N, Perelli R, et al. Technetium-thallium subtraction scan. A new method in the pre-operative localization of parathyroidto enlargement. Eur 7 Nucl Med 1981;6:A12.

${ }^{*}$ Makiuchi M, Miyakawa M, Sugenoya A, et al. Diagnostic usefulness or ${ }^{201}$ Tl-chloride scintigraphy for preoperative localization of parathyroidB tumors. Fpn $\mathcal{F}$ Surg $1981 ; 3: 162-6$.

${ }^{9}$ Ferlin G, Borsato N, Camerani M, Conte N, Tasca A. Parathyroiø scintigraphy with a new double-tracer $\left({ }^{99} \mathrm{Tc}-{ }^{201} \mathrm{Tl}\right)$ technique f Endocrinol Invest 1982;5:suppl No 1, 101

10 Robinson PJ. Parathyroid scintigraphy revisited. Clin Radiol 1982;33

1 Ell PJ, Todd-Pokropek A, Britton KE. Localization of parathyroid adeno-T mas by computer-assisted parathyroid scanning. Br f Surg 1975;62 553-5.

12 Beahrs O. Surgical management of hyperparathyroidism. Ann R Coll Surge्s Engl 1980;62:31-4.

${ }_{13}$ Brennan MF, Marx SJ, Doppman J, et al. Results of reoperation for persis-등 tent and recurrent hyperparathyroidism. Ann Surg 1981;194:671-6.

${ }^{14}$ Beazley RM, Costa J, Ketcham AS. Reoperative parathyroid surgery. Am $\overline{y \overline{\bar{D}}}$ Surg 1975;130:427-9.

15 Edis AJ, Sheedy PF II, Beahrs OH, van Heerden JA. Results of reoperation for hyperparathyroidism, with evaluation of preoperative localization studies. Surgery 1978;84:384-91.

${ }_{16}$ Wang C-A. Parathyroid re-exploration. Ann Surg 1977;186:140-5.

17 Brennan MF, Doppman JL, Kurdy AG, Marx SJ, Spiegel AM, Aurbach GD. Assessment of techniques for preoperative parathyroid glandw localization in patients undergoing reoperation for hyperparathyroidism. Surgery $1982 ; 91: 6-11$.

(Accepted 16 February 1983)
ONE HUNDRED YEARS AGO At the present time, when zymotic diseases are epidemic in many communities in the kingdom, it is especially important that sanitary authorities should recognise, remember, and effectually deal with, all possible sources and channels from and by which infection may be conveyed from the sick to the healthy. It is well known that the specific contagions of most of the zymotic diseases prevalent in this country readily become attached to textile fabrics; that, in such relationship, they long retain their activity; and that clothes, for these reasons, are specially apt to form the media by which infectious diseases are spread. It is necessary to warn the public that clothes which are quite new are especially liable, under certain circumstances, which we are afraid are comparatively common and frequent, to be impregnated with the specific germs of zymotic disorders. It is a trade custom, which is especially in vogue in large towns, amongst tailors, dressmakers, and others who make clothes, to employ largely the services of out-door assistants. Under this system, materials are "given out" at shops to outworkers, who take the fabrics home, and there make them up into garments, which are finished, carried to the shop, and distributed to the customers. Such outworkers are usually poor persons, and they often live amid surroundings which practically make zymotic disease a perpetual circumstance of their existence. It can be no marvel that these poor assistants of tailors and dressmakers, with the payment of their toil often cut down to the lowest limit, and driven by the stress of poverty to work even when ill, sometimes infect or allow to be infected, through ignorance or recklessness, the materials on which they work. Scarlet fever and small-pox are the zymotic diseases which are especially apt to be spread under the conditions in question. This is so for the two following reasons: the subjects of scarlet fever and small-pox are very commonly able to do comparatively light work, such as needlework, especially in their own homes, and even upon their beds, during a considerable portion of the infectious stages of their illness; and the emanations from the subjects of scarlet fever and small-pox, which are conspicuously, if not solely, contagious, namely, the desquamated epidermis in the case of scarlet fever, and the desiccated crusts in the case of small-pox, are materies morbi which, relatively to the contagia of other zymotics, are very substantial, and especially liable to be caught and kept in the meshes of textile fabrics. That the source of public danger through new clothes, to which we draw attention, is very real and very widespread, those who have had practical experience in zymotic disorders amongst the poor can bear abundant testimony. The evil is one which, we are afraid, it will prove difficult completely to control. Much, however, might probably be done to minimise the public peril in question, if sanitary authorities duly recognised the part which the outworkers of tailors and dressmakers play in the propagation of zymotic diseases, and vigorously dealt with the difficulty on obvious prophylactic principles. In places where zymotic maladies are prevalent, and especially where scarlet fever or small-pox is epidemic, local health-committees should require the proprietors of tailoring and dressmaking establishments to supplye् lists of their outworkers' names and addresses; these known, the homes of such outworkers ought to be regularly visited and reporteo upon by representatives of the sanitary authority. (British Medical fournal, 1883 ;ii :441.)

ONE HUNDRED YEARS AGO The Dean of Bangor haso lately called public attention to the manifold evils which he conceives are being wrought amongst us by the prevalence of tea-drinking. His gloomy forebodings predict little less than our general physical an moral decadence as a people and nation if we persevere in our addiction to the pleasures of the tea-pot. While it is true that tea, like every otherbeverage, is liable to abuse, and that its abuse is likely to produce certain well-defined bodily derangements which long have been recognised by our profession, the maladies which are fairly traceable to the drinking of tea are relatively so trivial, that the melancholy views of the worthy dean will not find support either in general populars observation, or in medical experience. If tea be pure, and free from poisonous "facings," the daily drinking of an infusion of it, in anything like moderate quantity, is free from all risk, either immediate or remote. It is well known to medical practitioners that there is $a$ common form of dyspepsia, which is especially prevalent amongst theo poor, which is mainly due to the excessive consumption of tea. The subjects of this disorder are commonly found to have been trying to "live" chiefly on tea, which has been supplemented only by small, supplies of the coarsest solid food. Such poor persons drink tea with every meal, and between their meals, from an infusion which "stands" continuously, and which is consequently largely chargeos. with the astringent matters which tea-leaves freely yield on prolonged maceration. Under these circumstances, the excessive drinking of tea produces a variety of chronic gastric catarrh. In persons pre- $\omega$ disposed to the disorder, the consumption of strong tea will also undoubtedly produce and keep up palpitation of the heart. Thiso possible and removable cause of cardiac derangement should alwaysD be sought in the treatment of cardiac neuroses. These are the chief? and the utmost human ills from which tea-drinking is fairly responsible.0 On the other hand, infusion of tea is a harmless restorative ando stimulant, which has taken a high and lasting place amongst humand comforts. Properly used, it refreshes after fatigue, enlivens the dull and cheers the depressed, while it aids digestion, promotes the removal of effete material, and has some protective virtue against the extremes of heat and cold. No secondary depression follows these good effects. As an article of diet for soldiers on active service especially in hot climates, the value of tea has been often proved, and is attested by the highest authorities. (British Medical fournat 1883 ;ii:786.) 